14 Gilchrist AC, Hannaford PC, Frank P, Kay CR. Termination of pregnancy and psychiatric morbidity. Br J Psychiatry 1995; 167: 243-8.

15 Fergusson DM, Horwood $\sqcup$, Boden JM. Abortion and mental health disorders: evidence from a 30-year longitudinal study. Br J Psychiatry 2008; 193: $444-51$

16 Dwyer JM, Jackson $\mathrm{T}$. Unwanted pregnancy, mental health and abortion: untangling the evidence. Aust N Z Health Policy 2008; 29: 2
17 Munk-Olsen T, Laursen TM, Pedersen CB, Lidegaard Ø, Mortensen PB. Induced first-trimester abortion and risk of mental disorder. N Engl J Med 2011; 364: 332-9.

18 World Health Organization. Unsafe Abortion: Global and Regional Estimates of the Incidence of Unsafe Abortion and Associated Mortality, 2000 (4th edn). WHO, 2004.

19 House of Commons (2009) Parliamentary Debates (Hansard). Wednesday 15 July 2009. Volume 496, No. 112. House of Commons.

\section{psychiatry} in pictures

\title{
Thomas Chetcuti - an image in Maltese psychiatry
}

\section{Anne-Marie Scerri}

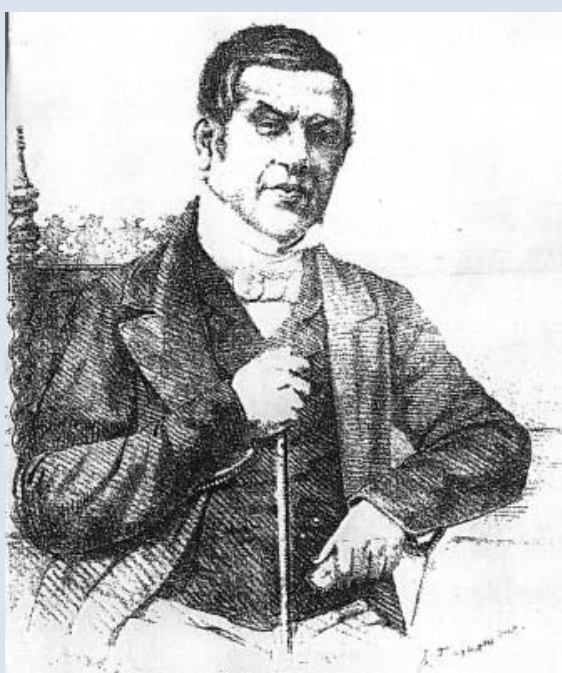

The 19th-century Maltese psychiatrist Thomas Chetcuti was born 3 years before the beginning of British rule in Malta, in 1797, in Mosta, a village in the centre of the island. He studied grammar, languages and classica poetry, as well as engaging in the study of philosophy and developing a great love for Christian literature. Having read law, he turned to pursuing medicine in Naples, to bring others to health and wholeness. He had a great interest in the works of Syndenham.

After completing his medical studies, he returned to Malta and was sought after by many for his great knowledge and diligence in the practice of medicine, obstetrics and ophthalmology. He soon became superintendent of Franconi House, a lunatic asylum in Floriana, a town on the outskirts of Malta's capital city, Valletta. Chetcuti remains greatly respected as the father of Maltese psychiatry and is fondly remembered as the one who removed restraints from psychiatric in-patients, limited the use of seclusion and introduced a more humane approach in psychiatric treatment, prohibiting maltreatment and the use of physical force on patients, and restoring their dignity.

As a researcher, chetcuti kept records of the people he encountered in his psychiatric practice, including statistical records. He was a loca implementer and advocate of what were at the time established treatments in psychiatry, including baths, emetics, purgatives, bloodletting, avoidance of constipation, exercise, psychotherapy and engaging patients in mentally stimulating activities. His enthusiasm and gentleness were key to his success in the treatment of his patients.

Chetcuti brought about reform in the asylum, but he was keen on moving it to the rural environment of what he called 'the splendid house of Incita Valley'. The new psychiatric hospital was built on the outskirts of the village of Attard, in the centre of the island. It survived to this day a large building with a grand main garden, surrounded by trees and open-air spaces, a comfortable and peaceful place with a splendid view of the hill on which Mdina, Malta's silent city with its ancient and majestic fortifications, was built, surrounding countryside and arable farmland - an ideal therapeutic setting for the treatment of menta illness.

As an appointed expert to the court of law, Chetcuti was sought for medical advice even within the remits of forensic psychiatry He was also a well-respected medical educator, his prime works on medical education being a text he wrote together with his colleague, Nicholas Zammit, as well as several addresses to medical students at the beginning of the academic year and addresses to the Medical Society of Encouragement. He was affiliated to several medical societies of the time. As an enthusiastic earner, Chetcuti also visited several asylums in England, France and Italy. His main psychiatric works include On the Manias, On Instinctive Homicidal Monomania, and Description of the Public Asylum of Malta.

Thomas Chetcuti died on 17 March 1863, following a period of illness during which patients still sought him for medical advice in his own home. It was when he noted the enlargement of his parotid and cervical glands that he realised he was approaching the end of his life, and asked for last rites. He was buried in Mosta parish church, where to this day a detailed inscription can be seen in the corridor joining the two sacristies.

(c) Image Malta Medical Journal. Reproduced with permission. 